\title{
Innovative technologies for low-rise construction
}

\author{
Aleksey Zhukov ${ }^{1}$, Timofey Dovydenko ${ }^{1}$, Sergey Kozlov ${ }^{1, *}$, Karapet Ter-Zakaryan ${ }^{2}$, and \\ Ekaterina Bobrova ${ }^{3}$ \\ ${ }^{1}$ Moscow State University of Civil Engineering, Yaroslavskoe shosse, 26, Moscow, 129337, Russia \\ ${ }^{2}$ TEPOFOL Ltd., 3 Shcherbakovskaya str., of. 606, 105318, Moscow, Russia \\ ${ }^{3}$ National Research University Higher School of Economics (NRU HSE), 20 Myasnitskaya Str., \\ 101000, Moscow, Russia
}

\begin{abstract}
The article presents the results of the implementation of promising areas of construction and construction of low-rise buildings. The problems of improving the environmental safety and financial stability of agricultural construction through the implementation of effective systems that provide energy conservation, the creation of comfortable conditions in the rooms are considered. It is noted that a factor that has been given special attention in recent years is the environmental safety of the materials used and the reduction of the negative load on the environment of systems using these materials. The article provides the rationale that the heatefficient system should not only be based on the use of materials with low thermal conductivity, but should also suggest a reasonable minimization of the joints between the products included in the insulation sheath and between products and structures. In constructions with the use of polyethylene foam, seamless insulating sheath is formed, which has high thermal resistance. The low vapor and wind permeability and moisture conductivity of polyethylene foam makes it possible to dispense with the construction without additional vapor barrier and wind protection, which improves the performance of the casing and its durability due to the reduction in the complexity of manufacturing wall structures.
\end{abstract}

\section{Introduction}

In the operation of residential facilities, it is important: preserving heat, creating comfortable conditions in the rooms, preserving the properties of building structures. Economic and social criteria, in this case, are reduction of energy expenditures for the operation of facilities (reduction in the incidence of staff) (reduction of hospitalization allowances and increase in work efficiency); increase in terms of maintenance-free operation of the constructed facilities [1-4].

A factor that has received special attention in recent years is the environmental safety of the materials used and the reduction of the negative load on the environment of the systems

\footnotetext{
*Corresponding author: ser-31-16@mail.ru
} 
using these materials [5-8]. Polyethylene is a neutral and non-toxic material that is used both in medicine and in the food industry, and its derivative, foam-ethylene, also has these properties. In constructions with the use of polyethylene foam, a seamless insulating sheath is formed, which has high thermal resistance. High thermal efficiency of these systems leads to energy savings, and, consequently, reduction of heat consumption and, consequently, fuel economy, which allows reducing the load on the environment by both reducing harmful emissions into the atmosphere and optimizing the production of carbohydrates $[9,10]$.

As part of the implementation of the food safety doctrine, it is equally important to preserve the harvest, that is, the construction of storage facilities that retain heat and contribute to the optimum temperature and humidity conditions of operation.

At the same time, the constructed objects (residential buildings, household and warehouse premises) must meet certain criteria, including:

- operation of all constructed objects is assumed year-round;

- optimization of the costs of construction and operation of these facilities should be optimized and pay off in a relatively short time;

- creation of an optimal microclimate in the rooms depending on the purpose and method of operation of the object.

\section{Experimental}

The main factor of energy saving is the use of building structures and their insulation systems based on highly efficient insulating materials (thermal conductivity no more than $0.06 \mathrm{~W} /(\mathrm{m} \cdot \mathrm{K}))$. Practice confirms that this is not enough, and that it is necessary to take into account heat loss through the joints of products and structures, mounting elements, etc. - through the so-called "cold bridges". Thermal imaging survey of constructed objects (Fig. 1) shows that through such "bridges" up to $30 \%$ of heat can be lost, which significantly reduces the thermal resistance of the structure and increases the heat engineering heterogeneity of such a design, and, as a result, doubts the heat engineering effectiveness of decisions made so beautiful looking on paper.
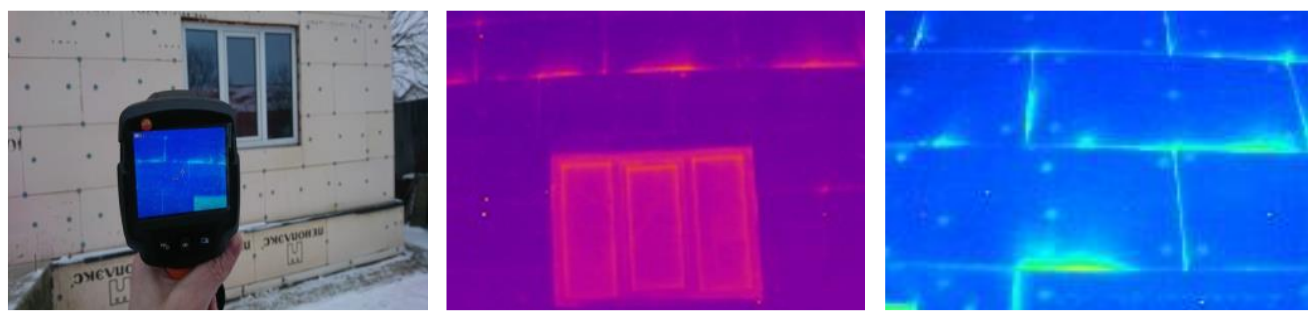

Fig. 1. Thermal imaging survey of the insulation shell: "bridges" of heat loss are clearly visible through the joints of the plates and through window and door openings.

Thus, the heat-efficient system should not only be based on the use of materials with low thermal conductivity, but also assume a reasonable minimization of joints both between the products included in the insulation sheath and between products and structures $[11,12]$.

There is a group of foamed or foaming polymers that allow the formation of a seamless insulating sheath. The connection of the insulating shell with the supporting structure is carried out either by adhesion (sprayed with foam-urethane), or by mechanical fastening (polyethylene, foam polypropylene).

Adhesive fastening is possible to realize only on the continuous bearing basis. The experience of using sprayed polyurethane foams showed that adhesive bonding is 
unreliable: delamination of the heat insulating layer is possible as a result of weakening of the adhesive contact during operation and due to the difference in temperature deformations of the base and insulating layer. When mechanically fixing elastic roll materials, the deformation of the base material (for a metal sheet - temperature, and for a wooden frame moisture) is accompanied by stretching of the elastic insulating sheath and no defects occur in the insulating layer.

The conditions for energy saving correspond to residential and household objects, based on the insulation systems of which is the use of rolled foam-polyethylene as heat- and steam- and waterproofing. This material not only possesses the necessary properties, but with its use, it becomes possible to create an insulating shell with high thermal engineering uniformity. Experimental studies on the possibility of using foamed polyethylen in the insulation systems of storage facilities and hangars, both frame and frameless, were conducted jointly with the National Research Moscow State University of Civil Engineering within the framework of the implementation of the economic agreement "Physical Research -mechanical characteristics of foamed polyethylene "Tepofol@" in systems of exterior and interior insulation ". Testing the properties of materials was carried out in accordance with GOST 17177-94. The object of the study was a heat-insulating material based on polyethylene (foamed polyethylene (PE)), as well as an insulation system using this material.

\section{Results}

The creation of a seamless insulating casing is achieved by combining polyethylene foam rolls (from 20 to $150 \mathrm{~mm}$ thick) with a locking compound (patent No. 2645190), followed by welding with a building fen. As a result of welding two rolls at a temperature of 110 $120^{\circ} \mathrm{C}$, a single seamless web is obtained $[13,14]$. This technology is used both in the isolation of household objects (warehouses, hangars, premises for livestock, agricultural products storage facilities) and in the insulation of frame cottages.

As already noted, the elastic insulating sheath is deformed together with the base. Products during operation experience tensile loads due to their thermal distortions. For the integrity of the insulation sheath, reliability of the welded joint between individual insulation panels (sheets, rolls). Tests of tensile strength in the longitudinal direction were carried out in accordance with GOST EN 1608-2011 "Heat-insulating products used in construction. Method for determining the tensile strength parallel to the facial surfaces ". Established. That tensile strength under tension in the longitudinal direction for products with a metallized coating is $80-92 \mathrm{kPa}$, without a metallized coating - 80- $-87 \mathrm{kPa}$, and for a weld - 29- $-32 \mathrm{kPa}$. Thus, the strength of a welded joint (recall that welding is carried out with a building block and hot air) is $30-35 \%$ of the tensile strength of the material itself. This is quite enough to preserve the reliability of the insulating shell, mechanically fixed to the supporting frame.

\section{Discussion}

Construction of frame cottages is one of the most economical way to build rural residential buildings. Calculations show that the price of $1 \mathrm{~m} 2$ of a frame cottage wall (Table 1) is significantly lower in comparison with the walls of autoclave cellular concrete blocks and bricks (ceramic stone) and layered facade systems. The traditional are insulation systems using mineral wool thermal insulation boards (Fig. 2). Insulation systems for frame structures differ from plastering systems and ventilated facades in that thermal insulation 
elements do not absorb mechanical stress. This makes it possible to use low and medium density materials with a minimum load on the base and low thermal conductivity.

Table 1. Comparative cost of various wall designs.

\begin{tabular}{|c|c|c|c|}
\hline \multirow{2}{*}{$\begin{array}{l}\text { Type of front (wall) } \\
\text { systems }\end{array}$} & \multicolumn{3}{|c|}{ Cost, rub / m2 } \\
\hline & $\begin{array}{l}\text { According to the } \\
\text { materials }\end{array}$ & By work & Total \\
\hline $\begin{array}{l}\text { Masonry from ceramic stones with } \\
\text { warming and brick lining }\end{array}$ & $3200-3300$ & $2500-2600$ & $5700-5900$ \\
\hline $\begin{array}{l}\text { SFTK (composite facade } \\
\text { insulation system (plaster with } \\
\text { insulation) on the bearing wall }\end{array}$ & $2600-2700$ & $2400-2500$ & $5000-5200$ \\
\hline $\begin{array}{l}\text { SVF (ventilated facade system } \\
\text { (with insulation) on the bearing } \\
\text { wall }\end{array}$ & $3200-3300$ & $3300-3400$ & $6500-6700$ \\
\hline Laminated wall & $2800-2900$ & $2400-2500$ & $5200-5400$ \\
\hline Wall of concrete blocks & $2200-2300$ & $2200-2300$ & $4400-4600$ \\
\hline Mineral wool insulation system & $700-750$ & $900-1050$ & $1600-1800$ \\
\hline $\begin{array}{l}\text { Frame system with insulation } \\
\text { based on polyethylene foam }\end{array}$ & $700-750$ & $700-850$ & $1400-1600$ \\
\hline
\end{tabular}

The density of mineral wool products for the roof is $40-60 \mathrm{~kg} / \mathrm{m} 3$, and for frame walls it is $50-70 \mathrm{~kg} / \mathrm{m} 3$. The strength of these products is low, which implies the protection of insulating layers not only from air and steam-air mixture, but also from mechanical loads. Otherwise, shrinkage and deformation of mineral wool plates, i.e., discontinuity of the insulation coating, is possible. Thermal engineering homogeneity is also reduced by the possible heat losses at the joints of the plates and in the places of their adherence to the supporting frame of the building.

Roll polyethylene polyethylene is placed on the outside of the frame (Fig. 2), mechanically fixed and welded with hot air. Next is mounted cladding of siding or other facade materials. Considering the low (compared to concrete or brick walls) load on the foundation, strip foundations of shallow lay are recommended, which also allows you to optimize the construction cost.
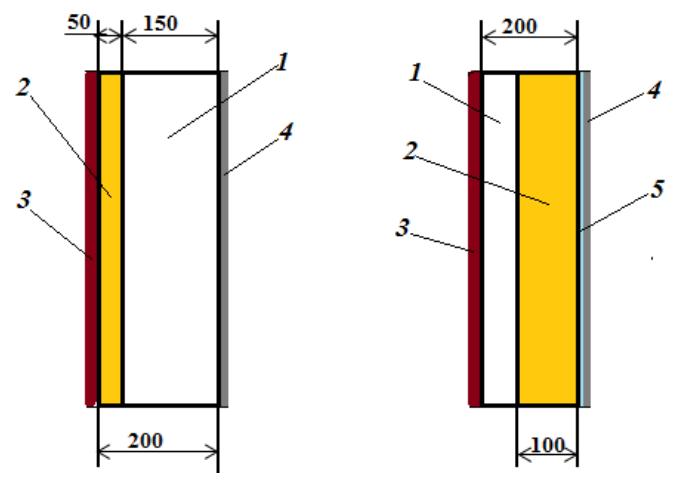

Fig. 2. Design schemes of facades with a frame wall: a - thermal insulation of unstitched polyethylene; $\mathrm{b}$ - mineral wool insulation; 1 - wooden frame member; 2 - heat insulation; 3 - outer lining; 4 - inner lining; 5 - vapor barrier.

Insulation systems for frame buildings with the use of plate products imply a mandatory vapor barrier from the inside and windscreen from the outside. This makes it possible to reduce the movement of the vapor-air mixture through the wall and the penetration of 
atmospheric air through the leaks of thermal insulation. The need to use additional insulating layers complicates the design and increases its cost (see Table 1).
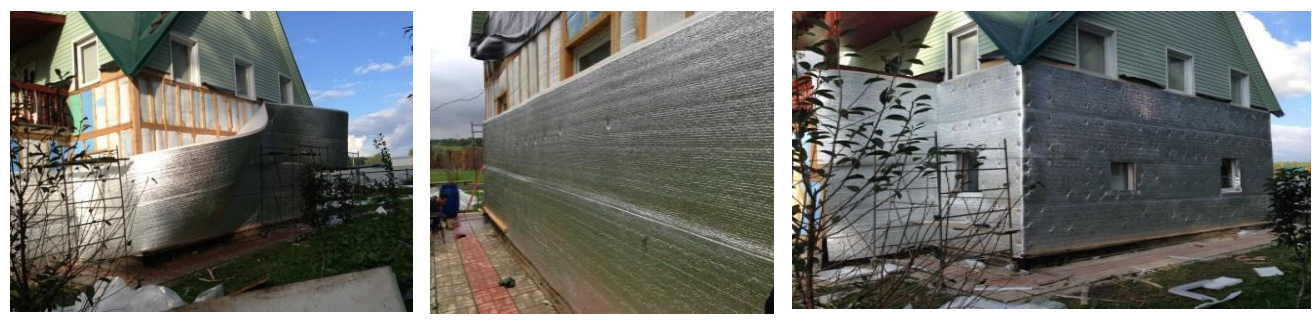

Fig. 3. Thermal insulation of the cottage: a - deployment of a roll of polyethylene foam; b mechanical fastening of thermal insulation and roll stitching; $\mathrm{c}$ - formation of an insulating contour and window openings.

A seamless insulating sheath based on rolled polyethylene foam is made in one layer, which allows optimizing the costs of installation and operation, and increases the durability of the insulation system (Fig. 3).

Various aspects of the use of polyethylene in facade systems were studied in the process of implementing contracts with NRU MGSU (department "SM \& M"): "Study of the physicomechanical characteristics of foamed polyethylene Tepofol ${ }^{\circledR}$ in exterior and interior insulation systems", as well as NIISF RAACS (laboratory "Stroyfizi-ka-TEST"): "Determination of the performance characteristics of the insulating material made of foamed polyethylene brand TEPOFOL." The studies concerned typical design solutions, the determination of the operational characteristics of the material, as well as the conduct of a field survey of a residential private house insulated with polyethylene foam.

\section{Conclusions}

As a result, of the research conducted, insulating systems were developed (which found wide practical application) and a full-scale thermophysical assessment of the thermal performance of these systems and the state of the wooden frame in the building after five years of operation was carried out.

The concept of long-term socio-economic development of the Russian Federation for the period up to 2020, involves the construction of low-cost and heat-efficient buildings, which makes it advisable to use technologies based on the concept of a seamless insulating shell based on polyethylene foam.

Insulation based on polyethylene foam is a durable material that is not deformed during the operation of buildings and structures, as well as being simultaneously heat- and vaporproof and waterproofing. The service life of the insulation of polyethylene foam is at least 50 years without additional repair work (restoration or complete replacement of insulation).

\section{References}

1. A.V. Kuchumov, E.S. Vorob'yova, Mosc. Economic J. 4, 266-277 (2018)

2. N.A. Ivanova, Mosc. Economic J. 4, 65-74 (2018)

3. P.M. Zhuk, A.D. Zhukov, Ecology and industry of Rus 4, 52-57 (2018)

4. A.D. Zhukov, V.S. Semenov, I.J. Gnip, S.J. Vaitkus, MATEC Web of Conferences 24, 117 (2017) 
5. B.M. Rumyantsev, A.D. Zhukov, D.B. Zelenshikov, A.S. Chkunin, K.K. Ivanov, Yu.V. Sazonova, MATEC Web of Conf., 86 (2016)

6. I.J. Gnip, V.J. Keršulis, S.J. Vaitkus, Mechan. of Com. Materials 4-41, 357-364 (2005)

7. I.J. Gnip, V.J. Keršulis, S.J. Vaitkus, Construction Materials 12, 40-44 (2012)

8. N.P. Umnyakova, V.M. Tsygankov, V.A. Kuzmin, Housing construction 1-2, 412-422 (2018)

9. S.E. Shmelev, Building Materials 3, 7-9 (2013)

10. A.D. Zhukov., E.Yu. Bobrova, D.B. Zelenshchikov, R.M. Mustafaev, A.O. Khimich, Advanced Materials. S. and M. Engineering 1025 - 1026, 1031-1034 (2014)

11. V.S. Semenov, T.A. Rozovskaya, A.Yu. Gubsky, Building Materials 6, 21-24 (2018)

12. A.D. Zhukov, K.A. Ter-Zakaryan, D.U. Tuchaev, E.S. Petrovskij, International Agricultural Journal 1(361), 65-67 (2018)

13. A.D. Zhukov, K.A. Ter-Zakaryan, A.V. Zayafarov, Ye.S. Petrovsky, D.U. Tuchaev, Insulation systems for pitched roofs. Roofing and insulation materials 6, 27-29 (2017) 